\title{
Creative innovation of startup businesses in Thailand 4.0 era
}

\author{
Pisit Potjanajaruwit \\ Faculty of Management, Suan Sunandha Rajabhat University, \\ Thailand \\ Pisit.po@ssru.ac.th \\ Luedech Girdwichai \\ Suan Sunandha Rajabhat University, \\ Thailand \\ Luedech.Gi@ssru.ac.th
}

Abstract. The objective of this research is to study the effects of creative innovation that influence the operations of startup businesses in Thailand 4.0 era. This research adopted mixed - methods approach, which includes qualitative research through in-depth interviews and quantitative research through data collection using questionnaire. The sample group set by the researcher are 404 entrepreneurs and managers who play an important role in the development of innovation and technology of startup business in Thailand 4.0 era. The data are analysed through Structural Equation Modeling (SEM) to confirm that information technology and Thailand 4.0 policy variables have direct positive effects towards creative innovation of startup business and creative innovation have direct positive effects on the performance of startup business. Besides, it was also found that information technology and Thailand 4.0 policy have indirect positive effects on the performance of emerging businesses through creative innovation where all the influential variables have statistical significance.

Keywords: creative innovation, STARTUP, Thailand 4.0, information technologies.

JEL Classification: G21, L26, O16 


\section{INTRODUCTION}

Emerging businesses such as startups and SMEs in the present days tend to carry out research and development more seriously as they place a lot of importance on growth and development of new innovations. For example, in South Africa, they try to connect innovations to the contemporary economic system to enhance the ability to drive overall economy, generate employment and revenues in the community to benefit majority of the people. Therefore, businesses must have high precision and accuracy when it comes to determining the strategies to develop and keep up with the pace of the modern world. This will also help in integration and expansion of market to the region with large-scale economy. Nevertheless, emerging businesses in the present times have to witness the development of local economy to solve the problems of local community by motivating entrepreneurs to use creative innovation for production of goods and services to serve the local market. With this reason, many SMEs try to run their businesses in consistence with the competitive economic condition and several of them have failed to survive this situation (Doblinger, Surana \& Anadon, 2019). The literature review conducted showed that (Nanda \& Rhodes-Kropf, 2013) in the United States of America, as many as $75 \%$ of the emerging businesses couldn't survive the market because they lacked sufficient information related to business strategic planning. Another reason for this failure is the fact that entrepreneurs lacked the knowledge of raw materials, skills and creative innovation to start a business. However, it is undeniable that there is a good numbers of SMEs that are able to develop and strengthen their businesses and eventually become large-scale businesses demonstrating stable growth. More than $80 \%$ of this originated from the operations of startups and SMEs and the remaining $20 \%$ are from various other businesses.

The problem related to the lack of skills in terms application of technology to create innovation is an important issue that affects SMEs and startup businesses because technology can shape creative innovation and thus reduce the cost of business operations whether in terms of production innovation, or process innovation, or management innovation. Additionally, it acts as a tool for systematic decisionmaking which could bring about competitive advantage as shown in the study of Fabrício, da Silva, Simões, Galegale and Akabane (2015). Their study that technology significantly affects creative innovation of business and plays important part in enhancing business value in terms of business operations as well as in creating more return on investment. Moreover, creative innovation generated out of information technology can also bring value to business financially and also in terms of customer satisfaction and better internal operations which are bound to become more stable and systematic. These are the proofs that innovation and technology have significance for businesses and economic growth overall.

The next reason responsible for the failure and shutting down of many startup businesses is the lack of understanding on the application of technologies to create innovation and the inability to see the correlation between the application of education and communication technology to support business operations in order to enhance business values. This is seen as a good opportunity for the business to develop itself and keep pace with the quick and aggressively changing technology. The last reason for the failure of SMEs is the fact that such businesses are unable to expand information technology resources due to insufficient funds because they failed to properly plan their IT budget from the beginning and this later affected the development of business especially in terms of limited creativity in education and communication. Finally it is undeniable that to get into the sources of investment funds, there must be support from various government policies in the fields of investment, entrepreneurship development research and development as well as upgraded business infrastructure is needed to support such development. 
Expansion rate of Gross Domestic Products in 2012-2016 percentage

\begin{tabular}{|c|c|c|c|c|c|c|c|}
\hline \multirow{2}{*}{ Number } & Enterprise type & \multicolumn{6}{|c|}{ Expansion rate of Gross Domestic Products in 2014- } \\
\cline { 3 - 8 } & & & & & & & Reduction rate \\
& & 2012 & 2013 & 2014 & 2015 & 2016 & \\
\hline 1 & Agriculture sector & 2.7 & 0.7 & -0.6 & -5.7 & 0.6 & $90.2 \%$ \\
\hline 2 & Non-agriculture sector & 7.8 & 3.0 & 1.1 & 3.9 & 3.5 & $43.68 \%$ \\
\hline 3 & Startups and SMEs & 7.6 & 3.2 & 0.9 & 5.2 & 4.8 & $46.52 \%$ \\
\hline
\end{tabular}

Source: Regnier, P., 2017. Small and Medium Enterprises in Distress: Thailand, the East Asian Crisis and Beyond: Thailand, the East Asian Crisis and Beyond. Routledge.

From Expansion rate of gross domestic products in 2012-2016 table, it was found that startups and SMEs have the gross value of $6,061,143$ million baht which accounts for $42.2 \%$ of the GDP. However, the statistics show a significant continuous drop in the rate of expansion from 2012 to 2016, which is the reduction rate of $46.52 \%$ (Regnier, 2017). The main factor responsible for the cause of this is the fact that the entrepreneurs of these emerging businesses lack the technology and creative innovation as well as having insufficient fund, techniques and some important factors needed for imports such as modern machinery (Jones \& Pimdee, 2017). The result of the absence of the abovementioned factors adversely affects the survival and performance of these startup businesses. Gehrich (2012) suggested that the lack of connection in terms of application of technology and governmental support tremendously affects the process of development of creative innovation in terms of production of goods, services as well as management, which could be a threat to the business in the future. Due to this, it is important to educate creative innovation to startup businesses in Thailand 4.0 era. The literature that was reviewed also showed that creative innovation issues affect the operation and existence of business.

This research aims to analyze and study issues related to the truth about the effects of creative innovation towards business performance, the ways in which it affects and the factors that influence creative innovation of that particular business. Therefore, the importance and the roots of the problems mentioned earlier gave rise to this research called "The Creative Innovation of STARTUP Business in Thailand 4.0 Era", focusing on providing beneficial and concrete knowledge to support the development of performance of creative innovation strategies for startup business in Thailand 4.0 era. The objectives of this research can be determined as follows to investigate the influence, factors and result of creative innovation towards the operation of startup business in Thailand 4.0 era.

\section{LITERATURE REVIEW}

\subsection{Creative innovation concept and theory}

The review of literature related to the creative innovation of startup businesses from the researches and academic journal papers found that Diaz Anadon (2019) has defined creative innovation as the invention and development of new products and services for the market for commercial purpose. This also includes the new procedures and ideas of management which conform to the studies of Adler, Florida, King and Mellander (2019) who added that creative innovation is using knowledge to invent new things to the market for commercial purpose by introducing new products, services and processes. These innovations must be the new ones that have never been presented to the market before and may be 
resulted from using new technological innovations, which benefits the majority in the society creatively. This also conforms with the study done by De Groote and Backmann (2019) who stated that creative innovation is an important factor to create competitive advantage and can build long-term relationship and customer loyalty towards the business, whether it is in terms of products, services, uniqueness or as well as service procedures and using technology to create innovations related to customer communication management. These all constitute important factors for business and economic growth. The study conducted by Ghezzi and Cavallo (2018) related to the ability of the entrepreneurs in coming up with new innovations as the factor that influences the performance of startup business revealed that creative innovation of startup entrepreneurs consist of product, service, procedures and management innovations which conform to the empirical data that influence the performance of business in terms of sales and customer satisfaction.

Additionally, it also helps facilitate the production procedures of goods and services that need time resources. Edison, Smørsgård, Wang and Abrahamsson (2018) also added that new entrepreneurs who wish to enter the market should start investing in research and development to find the gap in the market as well as needs that have not yet been responded. This also includes new innovations that are not out there yet such as products and services innovations, quick response process and service management or new business models to register for patent before moving to the next step of business. The literature review shows that creative innovation has relation with growth and survival of both existing and new businesses and also helps create sustainability to startup businesses that have just entered that particular industry by enhancing their survival ability and strengthen growth for the future. Bjornali and Ellingsen (2014) explained that with the current situation of globalization and keen competition, the SMEs and startups need to adapt themselves and invent creative innovation to produce goods and services to differentiate themselves in order to stirve in the changing business environment to maintain good financial performance, customer satisfaction and market share. Furthermore, Ahmadvand, Salami, Soofi and Tabatabaeian (2018) mentioned that innovation constitutes one of the competitive advantages of any business and helps build customer loyalty with long-term effect. Due to the fact that innovations are seen as one of the main factors driving economic growth, startups entrepreneurs must make use of creative innvation to develop their products and services to best respond the needs of customers and maintain good standards. QU (2018) who studied about the innovations that Influence the level of development of entrepreneurs and country investments revealed that creative innovations have correlation with growth of startup businesses. Currently, startup businesses face with changes related to customers and technologies which compelled them to improve and develop the production and quality of their goods and services on a continuous basis. Besides, they also need to consider the capital for production, the skills of the labor, relationship with partners and stakeholders. From the study Bandaranand Thomas (2018), it was found that most startup businesses still lack experience and personnel resources as well as sufficient capital needed to improve and develop products that are necessary to carry out creative innovation. Additionally, the operation of startup businesses needs to have competitive advantage in order to reduce the cost of production of goods and services while maintaining good quantity of production with limited time as well as focusing on good quality.

From all the reasons mentioned above, startup businesses must try to apply innovations and technologies to produce products and services that have uniqueness as well as using innovations and technologies to reduce the cost of production to result in competitive advantage and increase market share of the business. The study of Casanova, Cornelius and Dutta (2018) on the topic of creative innovation in terms of production procedures that influence the effectiveness of production found that innovations have significant relationship with the performance of production and also affect the expenses of 
productions that could further affect the overall capital and profits of the company. It was also revealed that creative innovation in terms of management arising out of using technology as the main factor in management also enhances the effectiveness of data management of the company. To support this, Fabrício Jr, da Silva, Simões, Galegale and Akabane (2015) who studied the issue of innovations that play important part in building competitive skills for startup businesses in Brazil revealed that creative innovation can build competitive skills for startup businesses with significant result and influence the results of startup business performance. Moreover, it also helps reduce cost of operations and innovations consist of four types, which are process innovations, product innovations, service innovations and management innovations. They also explained that a good creative innovation must be the one that can further be improved and can design existing products or services in such a way that they become better or have higher values. Nevertheless, enhancing the value of creative innovation as mentioned above may also cause changes in the operation of the business (Wajeetongratana, 2017).

\section{METHODOLOGY}

The creative innovation of startup business in Thailand 4.0 research adopted mixed methods approach, which includes qualitative research and quantitative research Creswell (2009). The researcher divided the study into 3 parts which are: first, gathered information from the entrepreneurs and managers who play important role in the development of innovation and technology of startup business in Thailand 4.0 era through qualitative research with the use of in-depth interview. This was done to find out the major factors that influence the occurrence of creative innovation of startup businesses in Thailand 4.0 era in order to create a quantitative questionnaire. Secondly, collected data from 404 businessmen who play important role in determining creative innovation such as the board, the manager, entrepreneurs and stockholders in order to find out the factors of creative innovation that influence the performance of startup businesses in Thailand 4.0 era (Potjanajaruwit, 2018). This was done using qualitative research by adopting survey research approach where the questionnaires were drafted with reference to the information gathered from first part. Thirdly, qualitative method was adopted by using focus group interview to confirm the effects of creative innovation that influence the operation of startup businesses in Thailand 4.0 era. The ultimate objective of this research is to get the results that would be beneficial for the society both academically and professionally in relation to creative innovation that affect the performance of startup businesses in Thailand 4.0 era. It is done by studying the main factors of creative innovation through in-depth interviews and confirming the concept by gathering information from the key informants which were chosen through purpose of sampling method and finally came down to three people who are business owner, manager and CEO of startup business.

Table 2

The emergence of startup businesses separated by regions

\begin{tabular}{|l|c|c|c|}
\hline Emergence of startup businesses separated by regions & $\begin{array}{c}\text { Number of } \\
\text { population }\end{array}$ & $\begin{array}{c}\text { Number of } \\
\text { sample } \\
\text { group }\end{array}$ & Percentage \\
\hline 1. Central region & 3,895 & 60 & 15.18 \\
\hline 2. Southern region & 6,338 & 83 & 21.01 \\
\hline 3. Northern region & 6,020 & 79 & 20.25 \\
\hline 4. Eastern region & 1,684 & 22 & 5.04 \\
\hline 5. North-eastern region & 12,240 & 160 & 40.50 \\
\hline Total & 30,177 & 404 & 100 \\
\hline
\end{tabular}


Source: Regnier, 2017. Small and Medium Enterprises in Distress: Thailand, the East Asian Crisis and Beyond: Thailand, the East Asian Crisis and Beyond. Routledge.

The researcher used the above information to analyze and build a structural equation model: SEM to find the cause and effect of creative innovation of startup businesses in Thailand 4.0 era. The theory and related researches were also studied to build own conceptual framework and determined that this model of research must be related to empirical data by using LISREL for Windows version 8.80 program and carried out assessment of model fit to verify the linear structural relationship of research model and empirical data. This was done by using Chi-square, $\chi^{2}$ /df, CFI, GFI, AGFI, RMSEA and SRMR.

\section{EMPIRICAL RESULTS AND DISCUSSION}

The analysis of the effects of the variables in the causal model of creative innovation of startup businesses in Thailand 4.0 era (direct, indirect and overall effects) according to hypothesis and empirical data revealed that such model conforms to the empirical data and when considering the model fit indices, it was found that the model conforms to the empirical data with 6 indices which are $/ \mathrm{df}=1.40$, CFI $=$ $1.00, \mathrm{GFI}=1.00, \mathrm{AGFI}=0.98, \mathrm{RMSEA}=0.032$ and $\mathrm{SRMR}=0.010$.

Therefore, it can be concluded that the structural equation model fits and conforms to the empirical data which can be explained as follows:

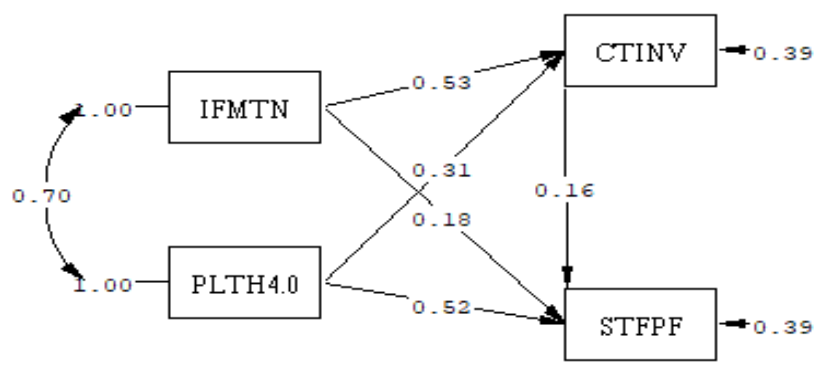

Chi-Square=1.40, df=1, P-value=0.23645, RMSEA=0.032

Figure 1. Analysis of the effects of variables of causal model of creative innovation of startup businesses in Thailand 4.0 era

When considering the direct effect that influence the creative innovation (CTINV), it was found that such variable received direct effect from information technology (IFMTN) and Thailand 4.0 policy (PLTH4.0) where the direct effect is equals to 0.53 and 0.31 respectively which are the values that have statistical significance of 0.01 .

Apart from the direct and indirect effects that influence creative innovation (CTINV), there are other variables that receive direct effects, which is startup businesses performance (STFPF) that is directly affected by information technology (IFMTN) and Thailand 4.0 policy (PLTH4.0) at the values of 0.18 and 0.52 respectively, which are the values that have statistical significance of 0.01 . Additionally, it is also directly affected by creative innovation (CTINV) at the value of 0.16 , which is the value that has statistical significance of 0.01. It is also indirectly affected by information technology (IFMTN) and Thailand 4.0 
policy (PLTH4.0) at the values of 0.08 and 0.05 respectively, which are the values that have statistical significance of 0.01 . Therefore, it can be concluded as follows:

(1) Information technology (IFMTN) has direct positive effect on creative innovation (CTINV) with direct influence value of 0.53 , which is the value that has statistical significance of 0.01 .

(2) Thailand 4.0 policy (PLTH4.0) has direct positive effect on creative innovation (CTINV) with direct influence value of 0.31 , which is the value that has statistical significance of 0.01 .

(3) Information technology (IFMTN) has direct positive effect on the performance of startup businesses (STFPF) with direct influence value of 0.18 , which is the value that has statistical significance of 0.01 .

(4) Thailand 4.0 policy (PLTH4.0) has direct positive effect on the performance of startup businesses (STFPF) with direct influence value of 0.52 , which is the value that has statistical significance of 0.01 .

(5) Creative innovation (CTINV) has direct positive effect on the performance of startup businesses )STFPF( with direct influence value of 0.16 , which is the value that has statistical significance of 0.01 .

(6) Information technology (IFMTN) and Thailand 4.0 policy (PLTH4.0) have indirect positive effects on the performance of startup businesses (STFPF) through creative innovation (CTINV) with indirect influence values of 0.08 and 0.05 respectively, which are the values that have statistical significance of 0.01 .

Table 3

The result of hypothesis testing

\begin{tabular}{|c|l|c|}
\hline No. & \multicolumn{1}{|c|}{ Hypothesis } & Result \\
\hline 1 & $\begin{array}{l}\text { Information technology has direct effect on creative innovation } \\
\text { of startup businesses in Thailand 4.0 era }\end{array}$ & Accept hypothesis \\
\hline 2 & $\begin{array}{l}\text { Thailand } 4.0 \text { policy has direct effect on creative innovation of } \\
\text { startup businesses in Thailand } 4.0 \text { era }\end{array}$ & Accept hypothesis \\
\hline 3 & $\begin{array}{l}\text { Creative innovation has direct effect on the performance of } \\
\text { startup businesses in Thailand } 4.0 \text { era }\end{array}$ & Accept hypothesis \\
\hline 4 & $\begin{array}{l}\text { Information technology has direct effect on the performance of } \\
\text { startup businesses in Thailand } 4.0 \text { era }\end{array}$ & Accept hypothesis \\
\hline 5 & $\begin{array}{l}\text { Thailand } 4.0 \text { policy has direct effect on the performance of } \\
\text { startup businesses in Thailand } 4.0 \text { era }\end{array}$ & \\
\hline
\end{tabular}

\section{CONCLUSION}

The research on creative innovation of startup businesses in Thailand 4.0 era can be discussed in accordance to the research objectives as follows

Objective 1: To investigate the cause and effect of creative innovation that influences the performance of startup businesses in 4.0 era.

The result of the hypothesis testing revealed that information technology (IFMTN) has direct positive effect on creative innovation with statistical significance of 0.01 . While creative innovation is influenced by information technology at the value of 0.53 and all of these are direct effects at the value of 0.53. This implies that it would be good for the business to make use of information technology and Internet to increase their knowledge and pass on the knowledge which can make personnel in the organization have more creativity to produce goods and services. Some of the businesses have already started using tablets, computers and other IT devices to allow their personnel to make use of these electronic devices to educate themselves and find more information related to the job. Additionally, there 
is also application of online courses for staff training to enhance their knowledge related to their jobs and cloud computing has also started coming into the picture. The analysis of large database on the online platform such as customer behavior for planning the business effectively will provide positive effects on creative innovation of the business with statistical significance. This conforms to the study of Fabrício Jr, da Silva, Simões, Galegale and Akabane (2015) who explained that using information technology as one of the most important topics for various academic courses and for startup businesses can help reduce cost of production and cost of labor. It will also help enhance the values of the products and services as well as increasing the competitive advantage of the business. Some of the studies/reports have shown that information technology helps enhance the potential of business operation. The study of Ghezzi and Cavallo (2018) emphasized that information technology or information systems are not just tools but the techniques that require understanding before making decisions of investment although they could help tremendously in the operation of the business.

The study also revealed that Thailand 4.0 policy (PLTH4.0) factor has direct positive effect on creative innovation (CTINV) with statistical significance of 0.01 where creative innovation (CTINV) received overall influence from Thailand 4.0 policy (PLTH 4.0) at the value of 0.31 and all of these are the direct effects at the value of 0.31 . This implies that Thailand 4.0 policy which is the policy that focuses on delivering and developing complete set of technologies to startup companies, helps determine investment budget needed for research and development to improve the skills of entrepreneurs and elevating business innovations. Additionally, it is also designed to help support startup businesses that have creative innovation to enter the national innovation list, provide consultants to startup businesses as well as facilitating vocational institutes' roles in supporting the startup entrepreneurs. Upgrading technologies and improving production process positively and directly affect creative innovation (CTINV) with statistical significance and conforms to the 12th national economic and social development plan that emphasizes on the strategies for developing creative innovation for the startup businesses by motivating and supporting various aspects such as investment, research and development and upgrading infrastructures to allow these entrepreneurs to use technologies as a driving force for better creativity and innovation that can bring more values to economy. These have become National Research Agenda with the goals to develop creative innovation of entrepreneurs for commercial benefits (12th national economic and social development plan, 2017).

The study also showed that creative innovation (CTINV) has direct positive effects on the performance of startup businesses (STFPF) with statistical significance of 0.01 where performance of startup businesses (STFPF) received overall influence from creative innovation (CTINV) at the value of 0.16 and all of these are the direct effects at the value of 0.16 . This implies that it would be good for the business to make use of information technology and Internet to increase their knowledge and pass on the knowledge which can make personnel in the organization have more creativity to produce goods and services. Some of the businesses have already started using tablets, computers and other IT devices to allow their personnel to make use of these electronic devices to educate themselves and find more information related to the job. Additionally, there is also application of online courses for staff training to enhance their knowledge related to their jobs and also the use of ERP (Enterprise Resource Planning) helps analyze information necessary for planning the business. All of these have proved to have positive effects on the performance of startup businesses (STFPF) with statistical significance. The result conforms to the study of Ahmadvand, Salami, Soofi and Tabatabaeian (2018) who did the analysis on strengths and weaknesses of startup businesses and found that most of the challenges that happened are caused by creative innovation and competitive environment where information technology plays an important role in terms of education, communication, operational support and business operations. This also matches with the study of Bandera and Thomas (2018) who shed light that changes in information 
technology will affect the strategic planning of product life cycle of new startup businesses because information technology and operational technology of an organization can help serve creative innovations to the market continuously and eventually enables that particular business to adjust itself with the competitive market effectively. The direction was also suggested by the study of QU (2018) who confirmed that application of information technology in terms of communication and operational supports helps influence the creative innovation of the business and allows them to survive in the competitive environment better. Therefore, the changes in information technology affects the performance and survival of businesses, especially in their early stage or businesses that are new in a particular industry because it helps reduce operational costs by applying information technology to help in operation and communication with the consumers or third parties.

Since information technology and creative innovation proved to affect the performance of startup businesses with statistical significance, the boards or people who play a part in determining the creative innovation must place emphasis on the activities and staff training on information technology to facilitate the process of creative innovation which could bring great values to the business. Additionally, this will also help promote sustainable growth in terms of sales and enhance competitive potential to uniquely differentiate the business from the competitors in the same industry. Some examples of this are: using applications to gather information for staff training or using operational technologies in accordance with Thailand 4.0 policy etc. Additionally, businesses must also follow up and give importance to engaging with projects initiated by Thailand 4.0 policy which will support entrepreneurs in terms of improving the production process of goods and services to result in sustainable development. Recently, there has been a creation of business incubators for technologies to support creative innovation supported by the government to help develop the entrepreneurs, to carry out research and development as well as supporting investment by bringing more technologies to business operations. As a result, these incubators proved to help both existing and new entrepreneurs tremendously in the creation of creative innovation in terms of production of good and services as well as management. Furthermore, it also helps enhance competitive advantage and enables entrepreneurs to survive the fast-changing and dynamic business environment.

\section{ACKNOWLEDGEMENT}

The author would like to thank Assoc. Prof. Dr. Luedech Girdwichai, The President of Suan Sunandha Rajabhat University, Bangkok, Thailand for financial support. I would like to thank Asst. Prof. Dr. Prateep Wajeetongratana, the Dean of Faculty of Management Science for the full support in this research.

\section{REFERENCES}

Adler, P., Florida, R., King, K., \& Mellander, C. (2019). The city and high-tech startups: The spatial organization of Schumpeterian entrepreneurship. Cities, 87, 121-130.

Ahmadvand, E., Salami, S. R., Soofi, J. B., \& Tabatabaeian, S. H. (2018). Catch-up process in nanotechnology startups: The case of an Iranian electrospinning firm. Technology in Society, 55, 1-8.

Bandera, C., \& Thomas, E. (2018). The role of innovation ecosystems and social capital in startup survival. IEEE Transactions on Engineering Management, (99), 1-10.

Bjornali, E. S., \& Ellingsen, A. (2014). Factors affecting the development of clean-tech start-ups: A literature review. Energy Procedia, 58, 43-50.

Casanova, L., Cornelius, P. K., \& Dutta, S. (2017). Financing entrepreneurship and innovation in emerging markets. Academic Press.

Creswell, J. W. (2009). Mapping the field of mixed methods research. 
De Groote, J. K., \& Backmann, J. (2019). Initiating open innovation collaborations between incumbents and startups: How can David and Goliath get along?. International Journal of Innovation Management, 2050011.

Doblinger, C., Surana, K., \& Anadon, L. D. (2019). Governments as partners: The role of alliances in US cleantech startup innovation. Research Policy, 48(6), 1458-1475.

Edison, H., Smørsgård, N. M., Wang, X., \& Abrahamsson, P. (2018). Lean internal startups for software product innovation in large companies: enablers and inhibitors. Journal of Systems and Software, 135, 69-87.

Fabrício Jr, R. D. S., da Silva, F. R., Simões, E., Galegale, N. V., \& Akabane, G. K. (2015). Strengthening of Open Innovation Model: using startups and technology parks. IFAC-PapersOnLine, 48(3), 14-20.

Gehrich, A. P., Hill, M. J., McWilliams, G. D., Larsen, W., \& McCartin, T. (2012). Comparison of urodynamic volume measurements using room and body temperature saline: a double-blinded randomized crossover study design. Female pelvic medicine \& reconstructive surgery, 18(3), 170-174.

Ghezzi, A., \& Cavallo, A. (2018). Agile business model innovation in digital entrepreneurship: Lean Startup approaches. Journal of business research.

Huang, W. P., Yuan, Q., Tan, Y. L., Wang, J., Liu, G. L., Qu, G. L., \& Li, C. (2018). An innovative support technology employing a concrete-filled steel tubular structure for a 1000 -m-deep roadway in a high in situ stress field. Tunnelling and Underground Space Technology, 73, 26-36.

Jones, C., \& Pimdee, P. (2017). Innovative ideas: Thailand 4.0 and the fourth industrial revolution. Asian International Journal of Social Sciences, 17(1), 4-35.

Nanda, R., \& Rhodes-Kropf, M. (2013). Investment cycles and startup innovation. Journal of Financial Economics, 110(2), 403-418.

Potjanajaruwit, P. (2018). Competitive advantage effects on firm performance: A Case study of startups in Thailand. Journal of International Studies, 11(3), 104-111.

Regnier, P. (2017). Small and Medium Enterprises in Distress: Thailand, the East Asian Crisis and Beyond: Thailand, the East Asian Crisis and Beyond. Routledge.

Wajeetongratana, P. (2017). Environmental Accounting for Modern Business: Social Responsibility or Economic Competitiveness? (The Case of Thailand). International Journal of Ecological Economics \& Statistics, 38(4), 123-132. 